\title{
THE USE OF INTEGRATED ELECTRONIC DATA CAPTURE AND ANALYSIS FOR ACCELERATOR CONSTRUCTION AND COMMISSIONING: PANSOPHY FROM THE SNS TOWARDS THE ILC*
}

\author{
V. Bookwalter, B. Madre, J. P. Ozelis, C. Reece + \\ Thomas Jefferson National Accelerator Facility, Newport News, VA.
}

\begin{abstract}
Jefferson Lab has extensively used a proprietary webbased system (Pansophy) that integrates commercial database, data analysis, document archiving and retrieval, and user interface software, as a coherent knowledge management product during the construction of the cryomodules for the SNS Superconducting Linac, providing elements of process and procedure control, data capture and review, and data mining and analysis. With near real-time and potentially global access to production data, process monitoring and performance analyses could be pursued in a timely manner, providing crucial feedback. The extensibility, portability, and accessibility of Pansophy via universally available software components provide the essential features needed in any information and project management system capable of meeting the needs of future accelerator construction efforts, requiring an unprecedented level of regional and international coordination and collaboration, to which Pansophy is well suited.
\end{abstract}

\section{RECENT PANSOPHY DEVELOPMENTS}

\section{User Interface}

Jefferson Lab has been extensively using a proprietary web-based system (Pansophy) that integrates commercial database, data analysis, document archiving and retrieval, and user interface software, as a coherent knowledge management product during the construction of the cryomodules for the SNS Superconducting Linac and CEBAF and JLab FEL accelerator projects. As utilization increased over the past few years, the user interfaces to Pansophy were evaluated with the goal of improving efficiency and clarity. As a result a new GUI was developed with improved accessibility and menu organization. This new Pansophy user interface, part of which is shown in Figure 1, includes "fly-out" menus, utilizing Macromedia's Dreamweaver ${ }^{\mathbb{B}}$ and Fireworks ${ }^{\mathbb{B}}$ menu integration system, and direct access to each area of Pansophy without the need for a deeply hierarchical menu tree. Care was also taken to ensure cross-browser support and groundwork was laid for WWW and Section 508 compliance.

\section{Traveler Creation}

As previously discussed elsewhere [1][2][3], travelers are the primary data input component of Pansophy.
Travelers are created using specially designed MS-Word ${ }^{\circledR}$ templates which are then converted to $\mathrm{html} / \mathrm{cfm}$ format. New templates have been developed to make traveler creation easier, by incorporating macros to aid in the standardization of field names for data input. For example, a series of cavity serial numbers can be placed in a pull-down list, resulting in a consistent naming convention during production. These conventions facilitate query and report development.

\section{Data Access and Analysis}

With thousands of pieces of data collected for an individual project, data retrieval to facilitate feedback and enhancements of production and processing activities becomes a high priority. Newly developed query capabilities and report generation assists in data mining.

Reports provide standard overviews of production and test data. These reports include:

- $\quad$ cavity processing/rinsing data - displays selected parameters related to the high pressure rinsing of cavities

- $\quad$ serial numbers - displays a complete list of part serial numbers used in the assembly of a particular cryomodule

- cavity performance - displays an overview of cavity performance during $2 \mathrm{~K} R \mathrm{R}$ testing.

- cryomodule performance - displays an overview of cryomodule performance during $2 \mathrm{~K}$ RF qualification testing.

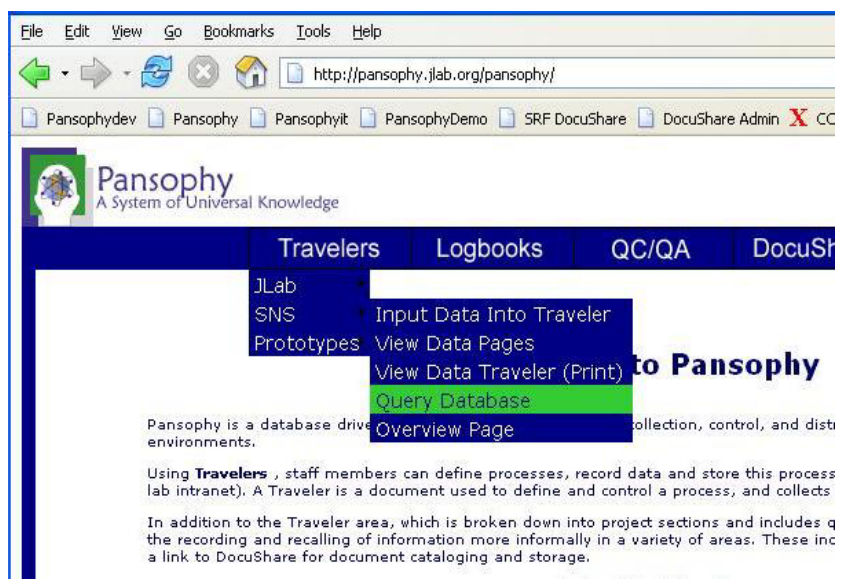

Figure 1.) Pansophy Home Page showing fly-out menu

\footnotetext{
* Work supported by U.S. Department of Energy under contract DE-AC05-84ER40150 ++ bookwalt, madre, ozelis, reece@jlab.org
} 


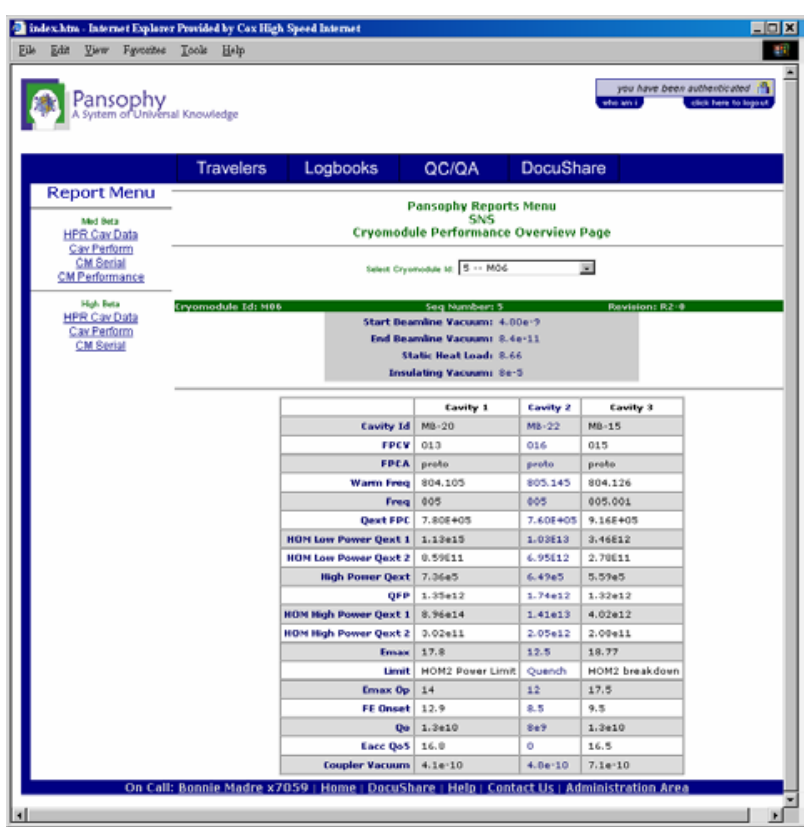

Figure 2.) Reports overview with the Cryomodule Performance Overview Report selected.

These reports allow managers and technical staff to monitor the progress of production and test results, providing a direct flow of information between production or test and project staff. Figure 2 shows the report selection menu interface with the Cryomodule Performance overview selected. Other report options can be seen on the left side of the screen.

New and enhanced queries include user-defined views of a single traveler revision, cross-revision queries that enable examination of a single traveler type across multiple revisions, and the cross-traveler query which enables the tracking of accelerator components across travelers (and hence processes or activities), and revisions of the same traveler.

\section{Production and Operations Support Modules}

In response to requests from other groups, modules to assist in other aspects of the Institute's activities, besides providing for production process control and data acquisition, have been added to Pansophy. Electronic logbooks, which now allow larger text fields for log entries, are available for system maintenance and facilities operations in addition to production documentation. The Equipment Calibration module has been enhanced to provide the means to track maintenance costs. An inventory application, previously a stand-alone commercial product, has been added recently, which allows the tracking and control of accelerator components through the construction process.

\section{Database Component}

Pansophy was originally configured so that the choice of commercial DBMS component would not restrict or hinder further development, by committing the product to any proprietary technology for the user interface. Initially, Ingres ${ }^{\circledR}$, was chosen simply because it was already in use at the lab, hence readily available, along with a large base of experienced users and administrators. It became clear, however, that if Pansophy were to eventually be utilized at other sites, a more portable and universally available database software was needed. The recent switch of the Pansophy DBMS from Ingres ${ }^{\circledR}$ to Oracle $^{\circledR}$, the most widely used DBMS, makes future incorporation of Pansophy at other collaborators' sites seamless.

\section{Direct Data Upload}

While production and test data had already been easily uploaded through the electronic travelers to the database as file attachments, an additional enhancement was added to provide direct data upload to the DBMS. The cavity vertical test data, the first take advantage of this feature, were uploaded into the DBMS from files generated by Labview $^{\circledR}$ data acquisition programs. A user interface was then added which allowed users to retrieve data for export into Excel or other program for graphing and analysis.

\section{File Attachments}

Previously, static documentation such as procedures, drawings, and specifications, were stored in collections on DocuShare ${ }^{\circledR}$, a commercial document sharing and archival system, and hyperlinked to the online travelers. While useful internally, this was not a portable arrangement, since document management strategies differ between organizations. To facilitate the utilization of Pansophy at other sites, the static documentation was moved into a separate directory structure within the Pansophy file system. This allows the entire system to be migrated to other locations, without requiring the purchase of a second document management system.

\section{UTILIZATION OF PANSOPHY IN SNS CRYOMODULE FABRICATION PROJECT}

Pansophy was used extensively at Jefferson Lab during the fabrication of the cryomodules for the SNS Linac, providing a key element of the QA program [4]. Pansophy was used to control and record data from production and test activities, QC inspections and nonconformances, and provide data analysis for production feedback. The query functions of Pansophy have facilitated the analysis of cavity and cryomodule performance [5][6].

Other than vendor documentation, which was supplied in hardcopy form, all of the project's cavity and cryomodule fabrication and assembly documentation generated by JLab was in electronic form and integrated with Pansophy. This then made it feasible to transfer the information to the SNS via electronic means. During the fabrication stages of the SNS project, the information contained in Pansophy was initially made available to select SNS personnel residing offsite. Staff members at SNS were able to access travelers and relevant logbooks from Oak Ridge. The access control design permitted 
$\mathrm{read} / \mathrm{write}$ permission to very specific areas of Pansophy, for the SNS staff, while restricting access to all others. This proved useful when, for example, the effort for conditioning of high-power couplers for the cryomodules was transferred to SNS. The functional availability of Pansophy at SNS meant that all data and procedures associated with coupler conditioning were available to SNS staff, and the data from coupler conditioning could be directly recorded into the database.

\section{EXTERNAL COLLABORATOR ACCESS}

It is widely recognized that many, if not most, future accelerator projects will involve collaborations and partnerships between various national and international laboratories and industrial partners. The LHC and SNS are existing examples, while the ILC perhaps serves as the ultimate manifestation of this phenomenon. From the outset, Pansophy has been designed and developed to accommodate and support collaborations, by utilizing commercial and widely available software tools, and being accessible via the WWW. Recently the complete cryomodule assembly and test database, along with all supporting html and Cold Fusion ${ }^{\circledR}$ files and programs, have been transferred to and installed at the SNS, where they function identically to the original installation at JLab. This crucial first step in utilizing Pansophy as a collaboration tool has been an unqualified success, and the SNS is presently utilizing the query functionality during Linac commissioning.

\section{PANSOPHY Inter-Lab Connectivity}

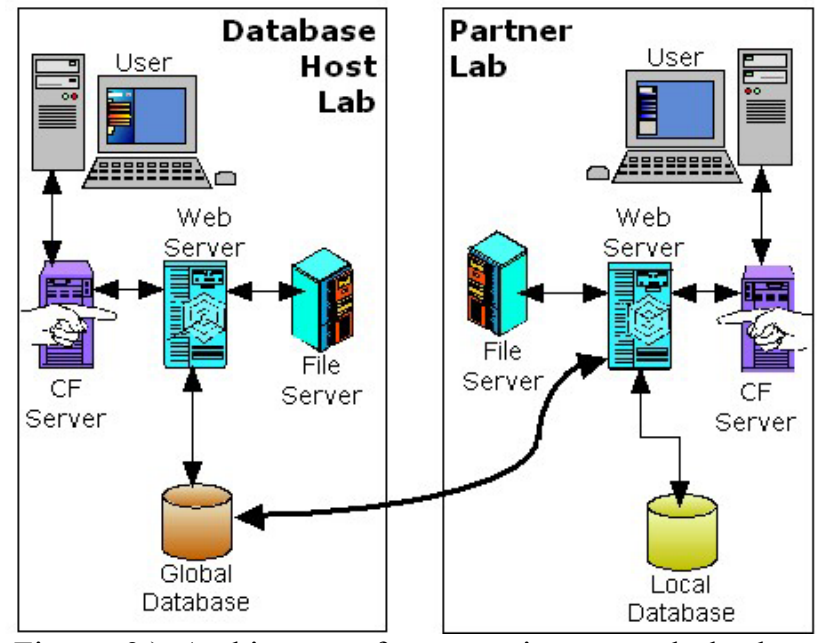

Figure 3.) Architecture for accessing central database from remote partner sites using local interface programs and analysis tools.

While the SNS experience demonstrates that the data, user interfaces, and software tools can easily be ported to another institution, the ultimate demonstration of Pansophy as a central tool for managing and achieving comprehensive and coordinated data management for a major international collaboration requires that multiple sites be able to access the underlying database using their own interfaces running on local serves. A model for such an architecture is shown in Figure 3. Under such a scheme labs, universities, and industrial partners could develop custom interface applications that suited the local information processing, data acquisition, and analysis needs and environment, while maintaining access to the central data repository.

\section{FUTURE DEVELOPMENT}

In addition to defining the structure to allow simple and universal access to the database for external collaborators using local servers and programs, a series of additional enhancements to Pansophy are being pursued. These include :

- $\quad$ automatic and continuous data uploads from data acquisition, diagnostic and monitoring equipment

- develop a custom user interface for date entry and retrieval on tablet PC's

- expand report and query capability to provide userdefined reports, and a library of stored frequently used queries, as well as user saved queries

- protection of intellectual property by limiting access to proprietary data to approved users

Pansophy has evolved from an internal system for managing data and information from cavity and cryomodule development into an accessible, intuitive, powerful, and portable tool ideally suited for use by global accelerator development and construction collaborations.

\section{REFERENCES}

[1] C. Reece, V. Bookwalter and B. Madre, "A System for Managing Critical Knowledge: Pansophy”, Proc. 2001 Part. Acc. Conf., Chicago, IL, June 2001.

[2] V. Bookwalter, B. Madre, J. P. Ozelis, C. Reece, "Utilization of Integrated Process Control, Data Capture and Data Analysis in Construction of Accelerator Systems", Proc. 2003 Part. Acc. Conf., Portland, OR, May 2003.

[3] B. Madre, V. Bookwalter, J. P. Ozelis, C. Reece. "Managing Critical Knowledge", presented at IADBG workshop as part of ICALEPCS 2001, San Jose, CA. December 2001.

[4] J. P. Ozelis, "The Jefferson Lab Quality Assurance Program for the SNS Superconducting Linac Accelerator Project", Proc. 2003 Part. Acc. Conf., Portland, OR, May 2003.

[5] J. Delayen, J. Mammosser, J. Ozelis, "Analysis of the Qualification Tests Performance of the Superconducting Cavities for the SNS Linac", Proc. LINAC 2004, Lübeck, Germany, August 2004.

[6] J. Delayen,. J. Mammosser, J. P. Ozelis, "Performance overview of the production superconducting RF cavities for the Spallation Neutron Source linac" paper PTTP079, this conference. 